\title{
КОРРЕКЦИЯ СТРЕСС-ИНДУЦИРОВАННЫХ НЕЙРОИММУНОЭНДОКРИННЫХ НАРУШЕНИЙ У САМЦОВ КРЫС С НИЗКОЙ УСТОЙЧИВОСТЬЮ К СТРЕССУ ПРИМЕНЕНИЕМ ТРАНСКРАНИАЛЬНОЙ ЭЛЕКТРОСТИМУЛЯЦИИ
}

\author{
(С) Липатова А.С., Каде А.Х., Трофименко А.И., Поляков П.П.
}

\author{
Кафедра общей и клинической патологической физиологии \\ Кубанского государственного медицинского университета, Краснодар \\ E-mail: a-lipatova@yandex.ru
}

\begin{abstract}
Цель работы - изучение эффективности транскраниальной электростимуляции (ТЭС-терапии) для коррекции стресс-индуцированных нарушений гормонального и цитокинового статуса у крыс с низкой стрессоустойчивостью. В исследовании задействовано 3 группы крыс: группа № 1 - интактные, группа № 2 (без ТЭС-терапии) и № 3 (с ТЭСтерапией) - с низкой стрессоустойчивостью. Проведено два теста принудительного плавания на 1 и 7 сутки, на 8 сутки - ортостатический стресс с последующим забором крови. Ортостатический стресс в группе № 2 сопровождался ростом: адреналина на 88,9\%, АКТГ в 10,5 раз, кортикостерона на 70,1\%, ИЛ-1 $\beta$ на 178,2\%, ИЛ-6 в 6,7 раза, ИЛ-10 на $37,1 \%$, в сравнении с контролем. В группе № 3 продолжительность плавания крыс выросла на 47,7\%. После ортостатического стресса выявлено снижение содержания: адреналина в 1,4 раза, АКТГ в 8,2 раза, кортикостерона в 1,4 раза, ИЛ-1 $\beta$ в 1,5 раза, ИЛ-6 в 2,2 раза, ИЛ-10 в 1,2 раза по отношению к группе № 2.
\end{abstract}

Ключевые слова: ТЭС-терапия, выносливость, стресс, АКТГ, кортикостерон, ИЛ-1, ИЛ-6, ИЛ-10, крысы.

\section{CORRECTION OF STRESS-INDUCED NEUROMIMUNE-ENDOCRINE DISTURBANCES IN MALE RATS WITH LOW STRESS SUSTAINABILITY BY TRANSCRANIAL DIRECT CURRENT STIMULATION \\ Lipatova A.S., Kade A.Kh., Trofimenko A.I., Polyakov P.P.}

Department of Common and Clinical Pathophysiology of Kuban State Medical University, Krasnodar

The goal of the research is to study the effectiveness of transcranial direct current stimulation (tDCS) for correcting stressinduced hormonal and cytokine disturbances in rats with low stress sustainability. There were 3 groups of rats: group 1 - intact, group 2 (without tDCS) and group 3 (with tDCS) - with low stress sustainability. Two forced swimming tests were carried out on days 1 and 7, on the 8th day - orthostatic stress with subsequent collection of blood. Orthostatic stress in group 2 was accompanied by growth: adrenaline by $88.9 \%$, ACTH 10.5 times, corticosterone by $70.1 \%$, IL- $1 \beta$ by $178.2 \%$, IL- 6 by 6.7 times, IL- 10 by $37.1 \%$, in comparison with the group 1 . In group 3, the duration of swimming of rats increased by $47.7 \%$. After orthostatic stress, a decrease in content was revealed: adrenaline 1.4 times, ACTH 8.2 times, corticosterone 1.4 times, IL-1 $\beta$ 1.5 times, IL-6 2.2 times, IL-10 in 1.2 times in relation to group number 2.

Keywords: tDCS, endurance, stress, ACTH, corticosterone, IL-1, IL-6, IL-10, rats.

Стресс - реакция организма на различные когнитивные, эмоциональные и соматические стрессоры, которая реализуется посредством активации единой нейроиммуноэндокринной системы и заключается в активации ряда физиологических и поведенческих программ, способствующих выживанию $[14,19,26]$.

Обусловленные стрессом изменения в функционировании симпатоадреналовой (САС), гипоталамо-гипофизарно-надпочечниковой (ГГНС) и иммунной систем сопряжены не только с адаптацией организма к новым условиям жизнедеятельности, но и риском развития ряда стрессассоциированных заболеваний [21]. При этом особую роль в развитии неблагоприятных проявлений стресса отводят активации реакции неспецифического воспаления, что в частности проявляется повышением уровня как провоспалительных, так и противоспалительных цитокинов [53].

Известно, что организмы с разными копингстратегиями в ответ на действие стрессоров реа- гируют по-разному, что определяет исход стресса [25]. Особенный интерес представляет изучение ответа на стрессор у животных с разной устойчивостью к стрессу, что открывает путь к поиску методов коррекции стрессоустойчивости у индивидов, обладающих активными и пассивными копинг-стратегиями.

Ключевую роль в контроле над развитием стресс-реакции играют опиоидные пептиды. Наибольшее количество опиоидных пептидов высвобождается в гипоталамусе, гипофизе и лимбических структурах головного мозга во время боли, стресса, а также при интенсивных физических нагрузках $[12,55]$. Стресс-лимитирующий эффект опиоидных пептидов опосредован активацией $\mu$ и $\delta$-опиоидных рецепторов, в отношении которых $\beta$-эндорфин проявляет высокую селективность $[42,55]$.

Выделяемый при развитии стресса $\beta$-эндорфин опосредует эндокринные и поведенческие реакции, направленные на адаптацию ор- 
ганизма к экстремальным условиям и способствует ограничению неблагоприятных проявлений стресса $[16,32]$. $\beta$-эндорфин стимулирует систему вознаграждения, ингибирует активность ГГНС, снижает уровень выделяемого кортикотропинрилизинг гормона и адренокортикотропного гормона (АКТГ), подавляет выраженность болевых ощущений и тревогу $[46,55]$.

В связи с выраженным стресс-лимитирующим эффектом опиоидных пептидов, поиск и исследование методов стимуляции активности эндогенной опиоидергической системы является актуальной задачей современной медицинской науки.

Транскраниальная электростимуляция (ТЭСтерапия) является физиотерапевтическим неинвазивным методом электрического воздействия через покровы черепа на мозг человека и животных, избирательно активирующим защитные (антиноцицептивные) механизмы мозга. Основные ее эффекты обусловлены усилением продукции $\beta$ эндорфина и сопутствующими изменениями продукции других нейротрансмиттеров: дофамина, норадреналина, серотонина, ГАМК и других $[2,4$, 8].

Цель исследования: изучение эффективности ТЭС-терапии для коррекции стресс-индуцированных нарушений гормонального и цитокинового статуса у крыс с низкой стрессоустойчивостью.

\section{МАТЕРИАЛЫ И МЕТОДЫ ИССЛЕДОВАНИЯ}

Исследование проведено на 182 трехмесячных самцах белых нелинейных крыс массой $195 \pm 15$ г, не имевших видимых признаков заболеваний. Животные содержались на базе вивария при температуре $22-24^{\circ} \mathrm{C}$ в условиях 12 -часового светового дня в пластиковых клетках с древесной стружкой по 5 особей в клетке, свободным доступом к пище (стандартный рацион) и воде, в условиях, исключающих воздействие стрессфакторов. Критериями исключения из эксперимента служили видимые анатомические дефекты и признаки болезней.

Bce эксперименты выполнялись в соответствии с требованиями приказа МЗ РФ от 01.04.2016 года № 199 и международными правилами «Guide for the Care and Use of Laboratory Animals».

В начале эксперимента проводили оценку выносливости и стрессоустойчивости животных с помощью теста принудительного плавания (ТПП) в модификации ФГБУН НЦБМТ ФМБА России $[3,5]$ и отбирали крыс с низкой стрессоустойчивостью, время плавания которых было меньше нижнего квартиля и не достигало $184 \mathrm{ce}-$ кунд $(\mathrm{n}=43)$. В качестве контроля использовали интактных крыс $(\mathrm{n}=10)$, отобранных из общей популяции методом случайных чисел [7].

Далее среди животных с низкой стрессоустойчивостью и выносливостью отобрали крыс в 2 группы: сравнения $(\mathrm{n}=8)$ и основную $(\mathrm{n}=9)$. Животные основной группы в течение 5 дней после проведения ТПП получали по одному сеансу ТЭС-терапии в день с использованием двухпрограммного электростимулятора «ТРАНСАИР-03» (ООО «Центр транскраниальной электростимуляции», г. Санкт-Петербург) по методике в собственной модификации [6].

На 7-е сутки эксперимента проводили 2-й ТПП и через 24 часа (на 8-е сутки) крыс обеих групп подвергали ортостатическому стрессу (OC). Для моделирования ОС крыс помещали в антиортостатическое положение под углом $90^{\circ} \mathrm{\kappa}$ горизонтальной поверхности в фиксаторах (рестрейнерах) из оргстекла размером 210х65х65 мм (ООО «НПК Открытая Наука») в течение 45 минут [1]. Забор крови осуществляли через 2 часа после ОС путем венесекции яремных вен под комбинированным инъекционным наркозом: золетил (тилетамина гидрохлорид и золазепама гидрохлорид) 20 мг/кг в/м («Virbac», Франция) и ксиланит (ксилазина гидрохлорид) 6 мг/кг в/м (ЗАО «НИТА-ФАРМ, Россия, г. Саратов). Наркоз верифицировали по угнетению роговичного рефлекса и исчезновению реакции на болевые раздражители (укол лапы) [6]. В качестве антикоагулянта использовали гепарин (РУП «Белмедпрепараты», Беларусь) из расчета 500 ЕД на 1 мл крови, далее кровь центрифугировали в течение 15 минут при ускорении 1000 g. Образцы полученной плазмы хранили в криопробирках при температуpe $80^{\circ} \mathrm{C}$ (рис. 1).

Количественное определение уровня адреналина и адренокортикотропного гормона в плазме крови осуществляли методом иммуноферментного анализа с помощью наборов Cloud-Clone Corp. (Китай), кортикостерона - Immunodiagnostic Systems Limited (Великобритания), ИЛ-1 $\beta$, ИЛ-6 и ИЛ-10 - eBioscience (Bender MedSystems GmbH, Австрия) на фотометре вертикального сканирования ANTHOS 2010 (Biochrom, Австрия) с помощью программного обеспечения ADAP Software, версия 2.0.

Статистическую обработку полученных данных осуществляли с помощью программного обеспечения «MS Excel 2016» (Microsoft, CША), «Statistica 10.0» (StatSoft Inc., США) и «GraphPad Prism 7.00» (GraphPad Software, Inc., США). Проверка нормальности распределения количественных признаков в исследуемых группах проводилась с использованием критерия Шапиро-Уилка. 


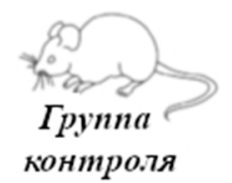

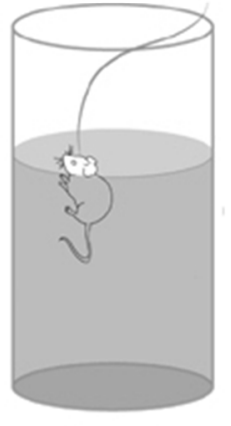

1 день

1-й тест

принудительного

плавания

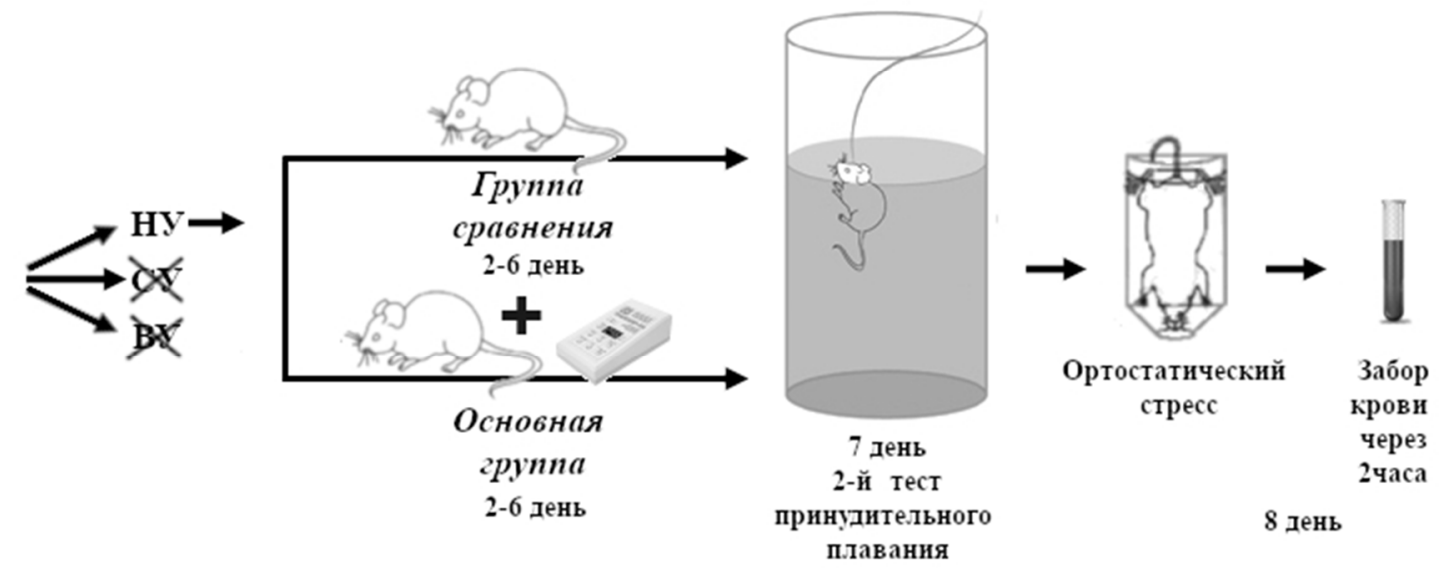

Рис. 1. Схема эксперимента.

Таблица 1

Время плавания у крыс с низкой стрессоустойчивостью и выносливостью в тесте принудительного плавания на 1-е и 7-е сутки

\begin{tabular}{|l|c|c|c|}
\hline \multicolumn{1}{|c|}{ Группа } & $\begin{array}{c}\text { Время 1-го плавательного теста, } \\
\text { Me (Q1-Q3), сек. }\end{array}$ & $\begin{array}{c}\text { Время 2-го плавательного теста, } \\
\text { Me (Q1-Q3), сек. }\end{array}$ & $\begin{array}{c}\text { p-value } \\
\text { (W-test) }\end{array}$ \\
\hline Сравнения & $161,5(146,5-171,5)$ & $166,5(160-215,5)$ & 0,05 \\
\hline Основная & $151(122-166)$ & $223(168-274)$ & 0,001 \\
\hline
\end{tabular}

Поскольку распределение значений отличалось от нормального, для дальнейших расчетов использовали методы непараметрической статистики. Полученные результаты выражали в виде медианы $(\mathrm{Me})$, нижнего и верхнего квартилей $(\mathrm{Q} 1$ и $\mathrm{Q} 3)$. Для оценки статистически значимых различий при парных сравнениях зависимых групп использовали критерий Вилкоксона (W-test), межгрупповых различий двух независимых групп - критерии Манна-Уитни (MW-test). Критический уровень значимости (p-value) при проверке статистических гипотез принимали равным $0,05[9,10]$.

\section{РЕЗУЛЬТАТЫ ИССЛЕДОВАНИЯ И ИХ ОБСУЖДЕНИЕ}

Проведение 5 сеансов ТЭС-терапии после первого ТПП у крыс с низкой стрессоустойчивостью статистически значимо (W-test, $\mathrm{p}=0,001$ ) приводило к увеличению времени плавания по результатам второго ТПП на 47,7\%, тогда как в группе сравнения статистически значимые изменения (W-test, $\mathrm{p}=0,05)$ отсутствовали (табл. 1 ).

Продолжительность плавания в ТПП во многом зависит от своевременного перехода от активного поведения (попытки выбраться и активное исследование аквариума) к пассивному (им- мобилизация на поверхности воды, экономный стиль плавания) [48].

По данным обзора de Kloet и Molendijk некорректно, как это делалось ранее, связывать повышение продолжительности иммобилизации (пассивный копинг) в тесте принудительного плавания с депрессивно-подобным поведением. Напротив, пассивная копинг-стратегия ассоциируется с повышением продолжительности плавания, а, следовательно, данная поведенческая программа способствует выживанию животного [25].

Проведение теста принудительного плавания вызывает значительный ответ со стороны СAC, ГГНС, а также ключевых нейромедиаторных систем головного мозга, в первую очередь дофаминергической [22]. Пристальное внимание к дофаминергической системе обусловлено ее ролью в патогенезе стресса и развитии стрессиндуцированных заболеваний, например депрессии [31]. Именно дофаминергическая нейротрансмиссия в лимбической системе мозга играет ключевую роль в переходе от активных к пассивным стилям поведения в тесте принудительного плавания [20, 25]. Известно, что взаимодействие $\beta$-эндорфина с $\mu$ - и $\delta$-опиоидными рецепторами стимулирует выработку дофамина [46]. 

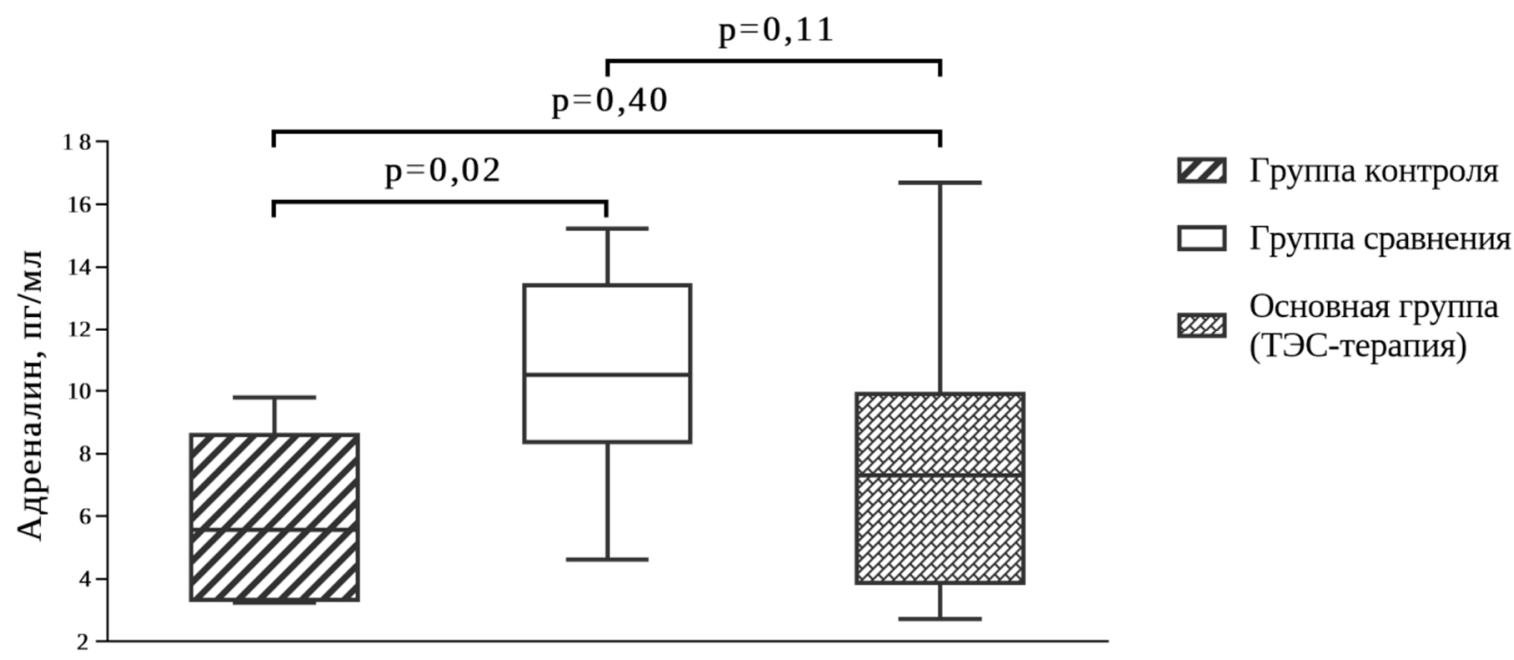

Рис. 2. Уровень адреналина в плазме крови крыс с низкой стрессоустойчивостью и выносливостью на 8 -е сутки эксперимента, через 2 часа после проведения ортостатического стресса.

Таким образом, можно сделать предположение, что рост продолжительности плавания у крыс, получавших ТЭС-терапию, обусловлен $\beta$-эндорфин-зависимой стимуляцией дофаминергической системы ствола мозга.

На 8-е сутки эксперимента, через 2 часа после проведения ОС уровень адреналина в плазме крови крыс из группы сравнения составил 10,52 пг/мл $(8,36-13,41)$, что статистически значимо на $88,9 \%$ больше (MW-test, $\mathrm{p}=0,02$ ) в сравнении с показателями группы контроля 5,57 пг/мл $(3,34-8,60)$. В основной группе уровень адреналина составил 7,30 пг/мл $(3,87-9,91)$, что в 1,4 раза меньше (MW-test, $\mathrm{p}=0,11$ ) в отношении группы сравнения (рис. 2).

Адреналин является гормоном, который высвобождается в ответ на стресс из мозгового вещества надпочечников в кровоток и опосредует краткосрочные ответы на стрессоры, инициируя ряд поведенческих и физиологических изменений, позволяющих организму реализовать программу «борьбы или бегства» [59]. Эффекты катехоламинов опосредованы взаимодействием с центральными и периферическими $\alpha$ - и $\beta$-адренорецепторами [27]. Следовательно, результатом повышения уровня циркулирующих катехоламинов - адреналина и норадреналина являются активация обмена и мобилизация энергии из депо, тахикардия, расширение зрачков, расширение бронхов и усиление дыхания, периферическая вазоконстрикция и перераспределение циркулирующей крови [44]. По данным литературы, высокий уровень катехоламинов в плазме крови ассоциирован с агрессивным поведением у крыс (активная копинг-стратегия) [41]. В группе крыс с использованием ТЭС-терапии достоверных изменений в концентрации адреналина по сравнению с группами контроля и сравнения не выявлено, что объясняется, тем что, забор крови проводился через 2 часа после ортостатического стресса и высвободившийся адреналин был в значительной степени метаболизирован [54]. Имеющуюся тенденцию к снижению концентрации адреналина в 1,4 раза в отношении группы сравнения, возможно обьяснить лимитирующим действием $\beta$-эндорфина на высвобождение катехоламинов, данный эффект достигается при его поступлении в кровяное русло [23].

На 8-е сутки эксперимента, через 2 часа после проведения ортостатического стресса уровень АКТГ в плазме крови крыс из группы сравнения составил 13,43 пг/мл (4,41-25,34), что статистически значимо в 10,5 раз выше (MW-test, $\mathrm{p}=0,02)$ в сравнении с показателями группы контроля 1,28 пг/мл $(0,96-2,58)$. В основной группе уровень АКТГ составил 1,63 пг/мл $(0,96-8,20)$, что статистически значимо (MW-test, $\mathrm{p}=0,02$ ) в 8,2 раза меньше в отношении группы сравнения (рис. 3).

На 8-е сутки эксперимента, через 2 часа после проведения ОС уровень кортикостерона в плазме крови крыс из группы сравнения составил 20,31 нг/мл $(18,62-36,82)$, что статистически значимо (MW-test, $\mathrm{p}=0,02$ ) на $70,1 \%$ выше в сравнении с показателями группы контроля 11,94 нг/мл $(10,60-15,94)$. В основной группе уровень кортикостерона составил 14,49 нг/мл $(11,06-21,28)$, что статистически значимо (MW-test, $\mathrm{p}=0,05$ ) в 1,4 раза меньше в отношении группы сравнения (рис. 4).

Активация ГГНС является отличительной чертой стресса и наблюдается при воздействии практически всех стрессоров как у животных, так и у человека [33]. Так, у крыс из группы сравнения, по отношению к животным из группы 
контроля, наблюдается статистически значимое повышение уровня АКТГ в 10,5 раз и кортикостерона на 70,1\%, что хорошо согласуется с данными литературы [11]. При этом как высокую, так и низкую реактивность ГГНС связывают с повышенным риском развития психических расстройств [29]. В отличие от катехоламинов, значительное повышение концентрации кортикостерона в крови наблюдается спустя десятки минут от воздействия стрессора, при этом его влияние является долговременным [13]. Кортикостерон реализует свои эффекты, связываясь с двумя типами рецепторов: высокоаффинными минералокортикоидными рецепторами I типа (MP) и низкоаффинными глюкокортикоидными рецепторами II типа (ГР) [24, 28]. МР и ГР в центральной нервной системе экспрессируются на нейронах, синтезирующих кортикотропин-рилизинг гормон и аргинин-вазопрес- син, локализованных в гипоталамусе, гипофизе, а также в структурах лимбической системы, которые, посредством дофаминергической системы, тесно связаны регуляцией поведения, в частности задействованы в переключении копинг-стратегии в условиях ТПП [15, 37, 45].

MP реагируют на низкие концентрации кортикостерона и способствуют процессу оценки угрозы и раннему ответу организма на стресс. ГР активируются высокими концентрациями кортикостерона и принимают участие в торможении стресс-реакции, возвращая секрецию кортикотропин-рилизинг гормона и АКТГ на исходный уровень по принципу отрицательной обратной связи, минимизируя их катаболические, липогенные, антирепродуктивные и иммуносупрессивные эффекты [17]. В целом относительно низкая плазменная концентрация кортикостерона связана c активной копинг-стратегией, тогда как,

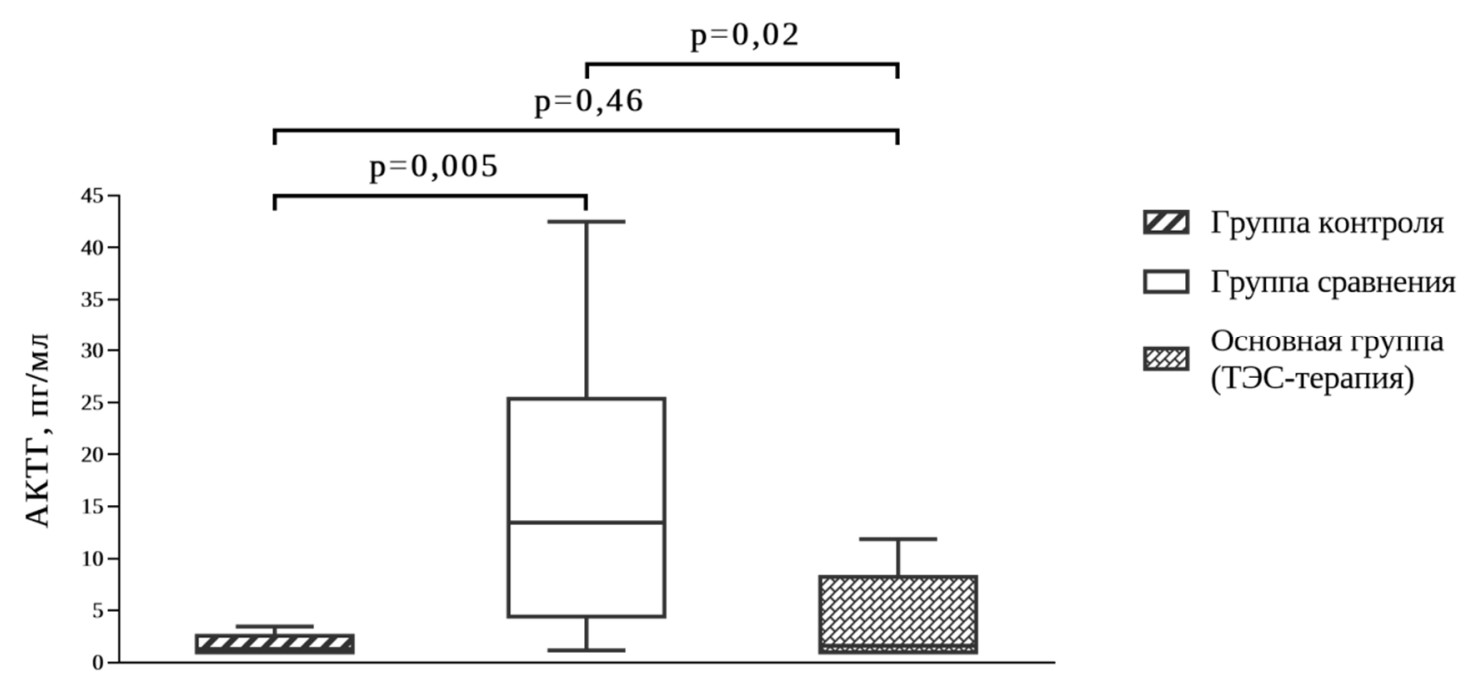

Рис. 3. Уровень АКТГ в плазме крови крыс с низкой стрессоустойчивостью и выносливостью на 8-е сутки эксперимента, через 2 часа после проведения ортостатического стресса.

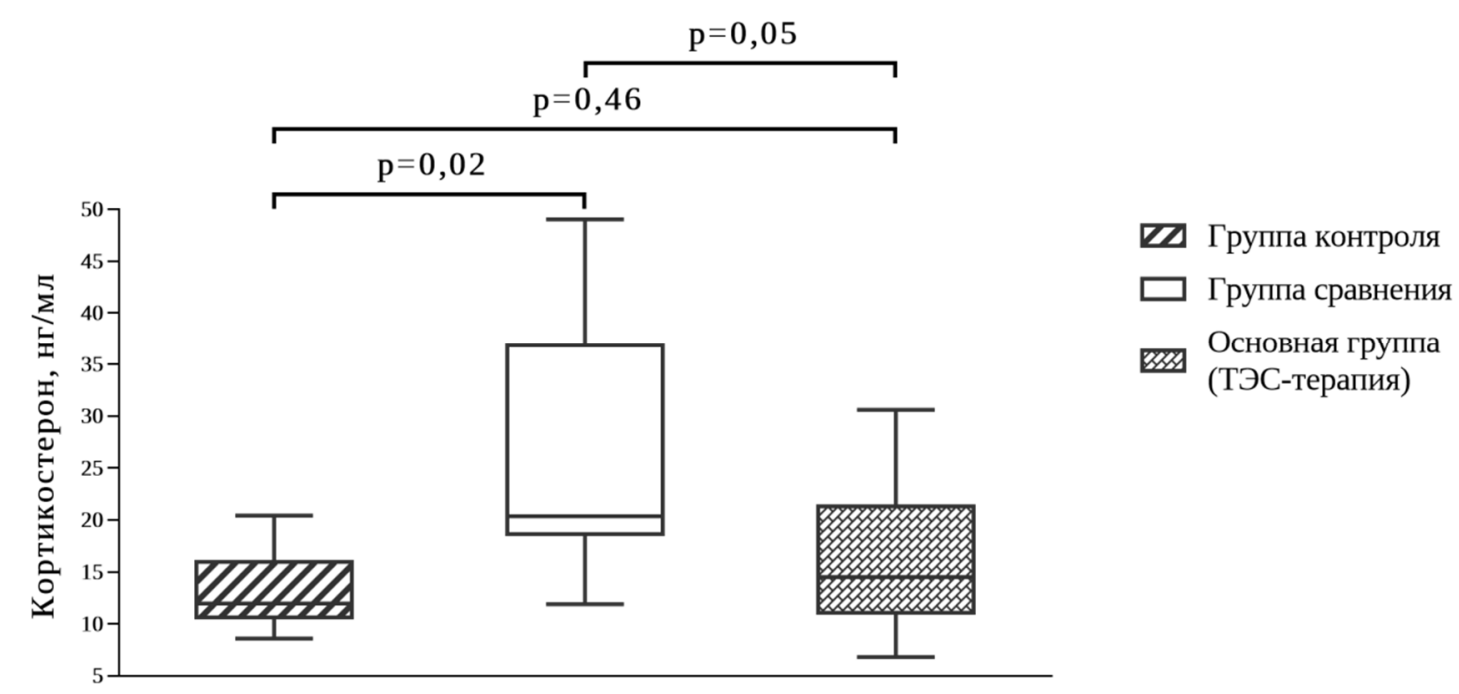

Рис. 4. Уровень кортикостерона в плазме крови крыс с низкой стрессоустойчивостью и выносливостью на 8-е сутки эксперимента, через 2 часа после проведения ортостатического стресса. 
повышение продолжительности иммобилизации в ТПП сочетается с высоким уровнем плазменного кортикостерона [40]. По данным литературы, повышение продолжительности плавания в ТПП (стратегия реактивного преодоления) связано с более высокой базальной и стимулированной активностью ГГНС [57]. Однако, по данным van Reenen, гиперактивность ГГНС в большей степени связана с уровнем агрессии, а не копингстратегией [56]. Это привело к разработке гипотезы баланса рецепторов кортикостероидов, гласящей, что при дисбалансе между МР/ГР в лимбической системе развивается расстройство нейроэндокринной регуляции стресс-реакции, что проявляется поведенческой дезадаптацией [25].

На 8-е сутки эксперимента, через 2 часа после проведения ОС уровень интерлейкина-1 $\beta$ (ИЛ-1 $\beta$ ) в плазме крови крыс из группы сравнения составил 12,13 пг/мл (9,80-17,07), что статистически значимо (MW-test, $\mathrm{p}=0,02$ ) на 178,2\% выше в сравнении с показателями группы контроля 4,36 пг/мл $(3,31-8,52)$. В основной группе уровень ИЛ- $1 \beta$ составил 7,87 пг/мл $(5,96-9,03)$, что статистически значимо в 1,5 раза меньше (MW-test, $\mathrm{p}=0,008)$ по сравнению с группой сравнения (рис. 5).

ИЛ-1 является центральным медиатором воспаления и играет важную роль в течении аутоиммунных, воспалительных, инфекционных и дегенеративных заболеваний. ИЛ-1 повышает продукцию других цитокинов участвующих в развитии воспаления, а также играет важную роль в патогенезе депрессии [18, 30]. В настоящее время собрано достаточно доказательств того, что ИЛ-1 играет важную роль в нейроэндокринных и поведенческих реакциях при стрессе. Рецепторы к ИЛ-1 обнаруживаются на всех уровнях ГГНС гипоталамусе, гипофизе и надпочечниках, что способствует стимуляции синтеза глюкокортикоидов. В то же время высокие концентрации глюкокортикоидов способны подавлять чрезмерный синтез ИЛ-1. Однако несмотря на тесное взаимодействие системы цитокинов и ГГНС, строгой корреляции между уровнями глюкокортикоидов и цитокинов, в частности ИЛ-1, установить не удается [34]. Установлено, что ИЛ-1 повышается при остром и хроническом стрессе, при этом низкие (физиологические) уровни ИЛ-1 являются адаптивными. Таким образом, блокада передачи сигналов ИЛ-1 может рассматриваться в качестве профилактики и лечения стресс-ассоциированных психических расстройств [39, 43].

На 8-е сутки эксперимента, через 2 часа после проведения ОС уровень интерлейкина-6 (ИЛ-6) в плазме крови крыс из группы сравнения составил 18,60 пг/мл $(8,43-23,41)$, что статистически значимо (MW-test, $p=0,005$ ) в 6,7 раза выше в сравнении с показателями группы контроля 2,79 пг/мл $(2,79-6,30)$. В основной группе уровень ИЛ-6 составил 8,43 пг/мл $(2,79-16,16)$, что статистически значимо (MW-test, $\mathrm{p}=0,05)$ в 2,2 раза меньше в отношении группы сравнения (рис. 6).

ИЛ-6 является провоспалительным цитокином, повышение уровня которого сопровождает течение как острого, так и хронического стресса [51]. Основными функциями ИЛ-6 являются активация пролиферации Т-лимфоцитов и дифференцировки В-лимфоцитов, стимуляция хемотаксиса лейкоцитов, повышение активности фибробластов и остеокластов, активация синтеза белков острой фазы, также он участвует в хронизации воспаления и контроле за массой тела [35].

ИЛ-6 участвует в модуляции поведения в ТПП, преимущественно способствует уменьшению продолжительности плавания, при этом его эффекты реализуются через миндалину или

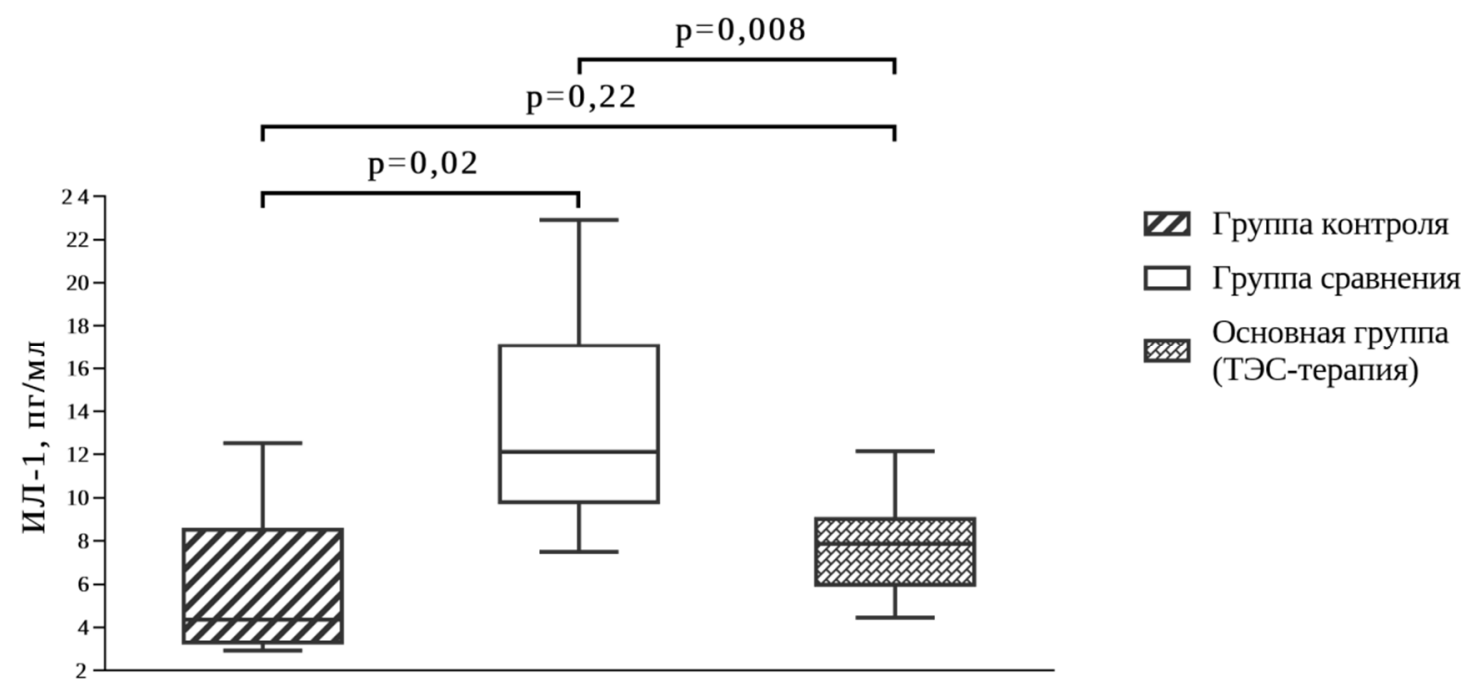

Рис. 5. Уровень ИЛ-1 в плазме крови крыс с низкой стрессоустойчивостью и выносливостью на 8-е сутки эксперимента через, 2 часа после проведения ортостатического стресса. 
гиппокамп, за счет активации сигнального пути Erk1/2 [60].

Выраженное повышение концентрации ИЛ-6 в крови отмечается при тревожных состояниях и депрессии [49].

Ряд исследований показывает, хотя регулярные физические нагрузки уменьшают воспаление и продукцию цитокинов, однако интенсивные упражнения способствуют продукции и высвобождению ИЛ-6 скелетными мышцами. В то же время ИЛ-6, образующийся во время физической активности, ингибирует продукцию ФНО- $\alpha$ и индуцирует продукцию ИЛ-10 [51, 38].

На 8-е сутки эксперимента, через 2 часа после проведения ОС уровень интерлейкина-10 (ИЛ-10) в плазме крови крыс как из группы сравнения, так и основной группы статистически начимо не отличался $\quad(\mathrm{p} \geq 0,05)$ от показателя группы контроля - 7,93 пг/мл $(6,83-8,42)$ и составил
10,87 пг/мл $(9,01-12,12)$ и 9,64 пг/мл $(6,43-12,12)$ соответственно (рис. 7).

ИЛ-10 является важным противовоспалительным цитокином, центральной ролью которого являются защита тканей от повреждения, вызванного инфекционными агентами и воспалением, заживление ран и предотвращение развития аутоиммунных заболеваний [50].

Отсутствие достоверных межгрупповых различий в концентрации плазменного ИЛ-10 предположительно свидетельствует о его второстепенной роли в развитии раннего ответа организма крысы на ОС. По данным литературы, повышение плазменной концентрации ИЛ-10 следует отсроченно, вслед за повышением плазменной концентрации провоспалительных цитокинов (ИЛ-1 $\beta$, ИЛ-6, ФНО- $\alpha$ ) [36]. При этом острый стресс, как показывают исследования, не оказывает выраженного влияния на уровень циркулирующего ИЛ-10 [58].

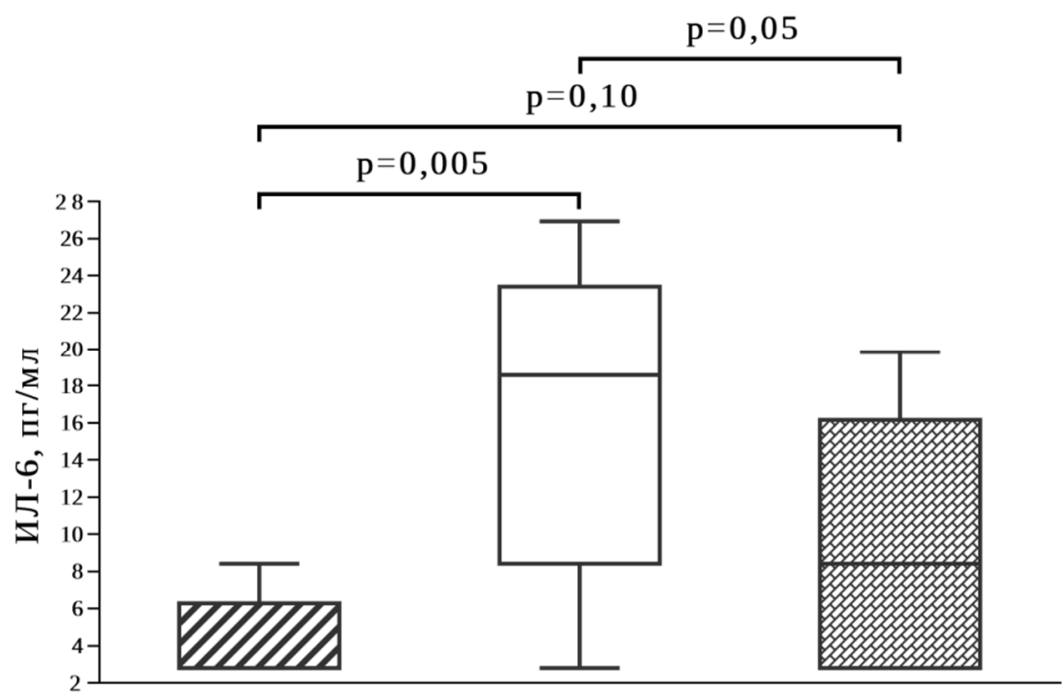

ש Группа контроля

$\square$ Группа сравнения

西

Основная группа

(ТЭС-терапия)

Рис. 6. Уровень ИЛ-6 в плазме крови крыс с низкой стрессоустойчивостью и выносливостью на 8-е сутки эксперимента через 2 часа после проведения ортостатического стресса.

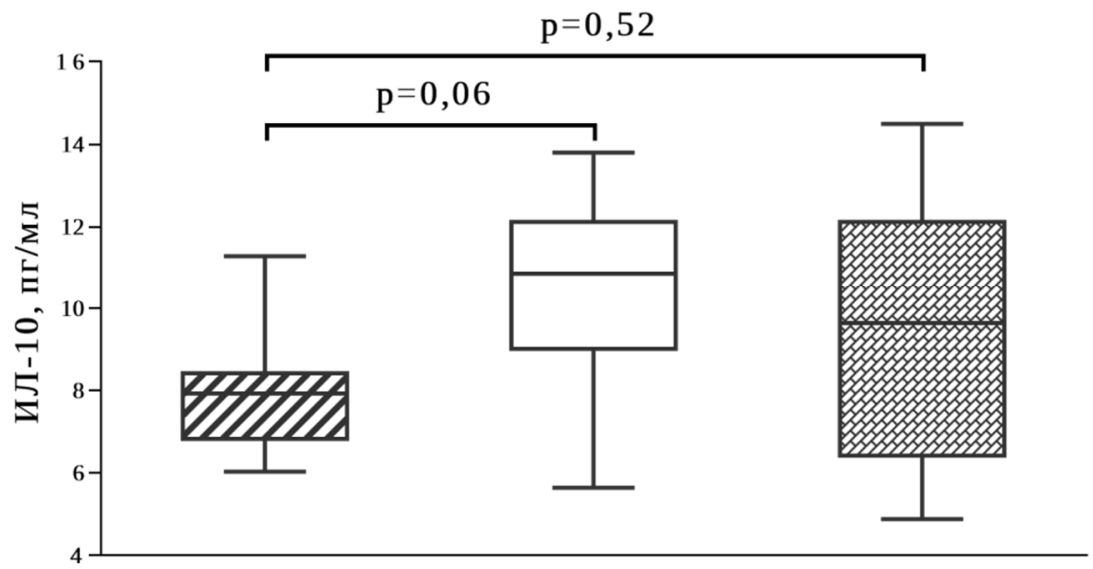

ש Группа контроля

$\square$ Группа сравнения

Основная группа (ТЭС-терапия)

Рис. 7. Уровень ИЛ-10 в плазме крови крыс с низкой стрессоустойчивостью и выносливостью на 8-е сутки эксперимента, через 2 часа после проведения ортостатического стресса. 
По данным A.R. Mesquita, в ТПП мыши нокаутные по гену ИЛ-10 показывали повышение продолжительности иммобилизации, которое нивелировалось путем введения ИЛ-10. У мышей с повышенной экспрессией ИЛ-10, изменения были противоположные нокаутным. При этом в обоих случаях найденная закономерность относилась к самкам мышей, а у самцов достоверной разницы в результатах ТПП получено не было [47].

По результатам первого ТПП, продолжительность плавания у крыс с низкой стрессоустойчивостью и выносливостью составила менее 184 секунд. Развитие ОС у крыс с низкой стрессоустойчивостью и выносливостью сопровождается ростом плазменного содержания: адреналина на $88,9 \%$, АКТГ в 10,5 раз, кортикостерона на 70,1\%, ИЛ- $1 \beta$ на $178,2 \%$, ИЛ-6 в 6,7 раза, ИЛ-10 на $37,1 \%$ в сравнении с группой контроля.

Проведение 5 сеансов ТЭС-терапии у крыс с низкой стрессоустойчивостью, по результатам второго ТПП, увеличивает продолжительность плавания на $47,7 \%$ и сопровождается снижением плазменного содержания: адреналина в 1,4 раза, АКТГ в 8,2 раза, кортикостерона в 1,4 раза, ИЛ$1 \beta$ в 1,5 раза, ИЛ-6 в 2,2 раза, ИЛ-10 в 1,2 раза по отношению к группе сравнения.

Полученные данные свидетельствуют о значительном потенциале дальнейших исследований ТЭС-терапии как метода повышения стрессоустойчивости и выносливости, профилактики стресс-ассоциированных заболеваний.

\section{ЛИТЕРАТУРА / REFERENCES}

1. Дигурова И.И., Гущчин А.Г. Влияние стрессоустойчивости на гемореологические показатели в норме и при ортостатическом стрессе // Ярославский педагогический вестник. - 2013. - Т. 3, № 1. - С. 107110. [Digurova I.I., Guschin A.G. Influence of stressresistance on hemorheological indices in norm and under orthostatic stress. Yaroslavskiy pedagogicheskiy vestnik. - 2013; 3(1): 107-110. (in Russ.)].

2. Занин С.А., Каде А.Х., Кадомиев Д.В., Пасечникова Е.А., Г Голубев В.Г., Плотникова В.В., Шаров М.А., Азаркин Е.В., Кочарян В.Э. ТЭСтерапия. Современное состояние проблемы // Coвременные проблемы науки и образования. 2017. - № 1. - С. 58. - Режим достуа: https://science-education.ru/ru/article/view?id=26133, свободный (19.04.2018). [Zanin S.A., Kade A.Kh., Kadomtsev D.V., Pasechnikova E.A., Golubev V.G., Plotnikova V.V., Sharov M.A., Azarkin E.V., Kocharyan V.E. TEBS-therapy. Current state of the problem. Sovremennyye problemy nauki i obrazovaniya. 2017; (1): 58. (in Russ.)].

3. Каркищенко В.Н., Капанадзе Г.Д., Деньгина С.Е., Станкова Н.В. Разработка методики оценки физической выносливости мелких лабораторных животных для изучения адаптогенной активности некоторых лекарственных препаратов // Биомедици- на. - 2011. - № 1. - C. 72-74. [Karkischenko V.N., Kapanadze G.D., Dengina S.E., Stankova N.V. Working out of a technique for physical endurance of small laboratory animals for studying of different medicine. Biomeditsina. - 2011; (1): 72-74. (in Russ.)].

4. Лебедев В.П., Савченко А.Б., Кацинельсон Я.С., Петряевская Н.B. Об опиатном механизме транскраниальной электроанальгезии у крыс и мышей // Физиол. журн. СССР. - 1988. - Т. 74. №. 9. - C. 1249-1256. [Lebedev V.P., Savchenko A.B., Katsnel'son Ya.S., Petryayevskaya N.V. On the opiate mechanism of transcranial electroanalgesia in rats and mice. Fiziol. zhurn. SSSR. - 1988; 74(9): 1249-1256. (in Russ.)].

5. Липатова А.С., Поляков П.П., Каде А.Х., Трофименко А.И., Кравченко С.В. Влияние транскраниальной электростимуляции на выносливость крыс с разной устойчивостью к стрессу // Биомедицина. - 2018. - № 1. - C. 84-91. [Lipatova A.S., Poljakov P.P., Kade A.H., Trofimenko A.I., Kravchen$k o S . V$. The infuence of transcranial direct current stimulation on the endurance of rats with different stress vulnerability. Biomeditsina. 2018; (1): 84-91. (in Russ.)].

6. Липатова А.С., Поляков П.П., Каде А.Х., Занин С.А., Трофименко А.И., Мальшева Т.В. Модификация методики ТЭС-терапии для ее применения у мелких лабораторных грызунов // Современные проблемы науки и образования. - 2015. № $5 . \quad$ - С. 347 - Режим доступа: https://www.science-

education.ru/ru/article/view?id=22696, свободный (19.04.2018) [Lipatova A.S., Polyakov P.P., Kade A.Kh., Zanin S.A., Trofimenko A.I., Malysheva T.V. Modification of the procedure TES-therapy for its use in small laboratory rodents. Sovremennyye problemy nauki i obrazovaniya. 2015; (5): 347 (in Russ.)].

7. Селезнева А.И., Макарова М.Н., Рыбакова А.В. Методы рандомизации животных в эксперименте // Международный вестник ветеринарии. 2014. - № 2. - C. 84-89. [Selezneva A.I., Makarova M.N., Rybakova A.V. Randomization of experimental animals. Mezhdunarodnyy vestnik veterinarii. 2014; (2): 84-89. (in Russ.)].

8. Трофименко А.И., Каде А.Х., Мясникова В.В., Пирогова Н.П., Занин С.А. $\beta$-эндорфин и цитокиновый профиль в динамике экспериментального ишемического инсульта // Современные проблемы науки и образования. - 2014. - № 6. - С. 1125. Режим доступа: https:/scienceeducation.ru/ru/article/view?id=16368, свободный (19.04.2018). [Trofimenko A.I., Kade A.Kh., Myasnikova V.V., Pirogova N.P., Zanin S.A. $\beta$-endorphin and cytokine profile in the dynamics of experimental is ischemic stroke. Sovremennyye problemy nauki i obrazovaniya. 2014; (6): 1125. (in Russ.)].

9. Трухачева Н.В. Математическая статистика в медико-биологических исследованиях с применением пакета Statistica. - М. : ГЭОТАР-Медиа, 2012. 384 с.: ил. [Trukhacheva N.V. Mathematical statistics in biomedical research using Statistica package. M. : GEOTAR-Media; 2012: 384 (in Russ.)]. 
10. Унгуряну Т.Н., Гржибовский А.М. Краткие рекомендации по описанию, статистическому анализу и представлению данных в научных публикациях // Экология человека. - 2011. - № 5. - С. 55-60. [Unguryanu T.N., Grjibovski A.M. Brief recommendations on description, analysis and presentation of data in scientific papers. Ekologiya cheloveka. 2011; (5): 55-60 (in Russ.)].

11. Abel E.L. Physiological correlates of the forced swim test in rats // Physiology \& behavior. - 1993. Vol. 54, N 2. - P. 309-317. - DOI: 10.1016/00319384(93)90116-W.

12. Anderson E.H., Shivakumar G. Effects of exercise and physical activity on anxiety // Frontiers in psychiatry. - 2013. - Vol. 4. - P. 27. - DOI: 10.3389/FPSYT.2013.00027.

13. Angelier F., Wingfield J.C. Importance of the glucocorticoid stress response in a changing world: theory, hypotheses and perspectives // General and Comparative Endocrinology. - 2013. - Vol. 190. - P. 118128. - DOI: 10.1016/j.ygcen.2013.05.022.

14. Bains J.S., Cusulin J.I.W., Inoue W. Stress-related synaptic plasticity in the hypothalamus // Nature Reviews Neuroscience. - 2015. - Vol. 16, N 7. - P. 377-388. DOI: $10.1038 / \mathrm{nrn} 3881$.

15. Bao A.M., Meynen G., Swaab D.F. The stress system in depression and neurodegeneration: focus on the human hypothalamus // Brain research reviews. 2008. - Vol. 57, N 2. - P. 531-553. - DOI: 10.1016/J.BRAINRESREV.2007.04.005.

16. Barfield E.T., Moser V.A., Hand A.,Grisel J. $\beta$-endorphin modulates the effect of stress on noveltysuppressed feeding // Frontiers in behavioral neuroscience. - 2013. - Vol. 7. - P. 19. - DOI: 10.3389/fnbeh.2013.00019.

17. Bonfiglio J.J., Inda C., Refojo D., Holsboer F., Arzt E., Silberstein $S$. The corticotropin-releasing hormone network and the hypothalamic-pituitary-adrenal axis: molecular and cellular mechanisms involved // Neuroendocrinology. - 2011. - Vol. 94, N 1. - P. 12-20. DOI: $10.1159 / 000328226$.

18. Bujak M., Frangogiannis N. G. The role of IL-1 in the pathogenesis of heart disease // Archivum immunologiae et therapiae experimentalis. - 2009. - Vol. 57, N 3. - P. 165-176. - DOI: 10.1007/s00005-009-0024$\mathrm{y}$.

19. Campbell J., Ehlert U. Acute psychosocial stress: does the emotional stress response correspond with physiological responses? // Psychoneuroendocrinology. 2012. - Vol. 37, N 8. - P. 1111-1134. DOI: 10.1016/J.PSYNEUEN.2011.12.010.

20. Campus P., Canterini S., Orsini C., Fiorenza M.T., Puglisi-Allegra S., Cabib S. Stress-induced reduction of dorsal striatal D2 dopamine receptors prevents retention of a newly acquired adaptive coping strategy // Frontiers in pharmacology. - 2017. - Vol. 8. P. 621. - DOI: 10.3389/fphar.2017.00621.

21. Carroll D., Ginty A.T., Whittaker A.C., Lovallo W.R., de Rooij S.R. The behavioural, cognitive, and neural corollaries of blunted cardiovascular and cortisol reactions to acute psychological stress // Neuroscience \& Biobehavioral Reviews. - 2017. - Vol. 77. - P. 7486. - DOI: 10.1016 / j.neubiorev.2017.02.025.
22. Connor T.J., Kelly J.P., Leonard B.E. Forced swim test-induced neurochemical, endocrine, and immune changes in the rat // Pharmacology Biochemistry and Behavior. - 1997. - Vol. 58, N 4. - P. 961-967. DOI: 10.1016/S0091-3057(97)00028-2.

23. Cozzolino D., Sasso F.C., Salvatore T., Torella M., Cittadini A., Gentile, S., Giugliano, D., Torella R., Giugliano D. Acute effects of $\beta$-endorphin on cardiovascular function in patients with mild to moderate chronic heart failure // American heart journal. 2004. - Vol. 148, N 3. - P. 530. - DOI: 10.1016/j.ahj.2004.01.029.

24. De Kloet E.R., Joëls M., Holsboer F. Stress and the brain: from adaptation to disease // Nature reviews neuroscience. - 2005. - Vol. 6 N 6. - P. 463-475.

25. De Kloet E.R., Molendijk M.L. Coping with the forced swim stressor: towards understanding an adaptive mechanism // Neural Plasticity. - 2016. - Vol. 2016. P. 6503162 - DOI: 10.1155/2016/6503162.

26. Everly Jr G.S., Lating J.M. A clinical guide to the treatment of the human stress response. 3rd Edn. New York: Springer Science \& Business Media, 2013. $-488 \mathrm{p}$.

27. Freeman J.V., Dewey F.E., Hadley D.M., Myers, J., Froelicher V.F. Autonomic nervous system interaction with the cardiovascular system during exercise // Progress in cardiovascular diseases. - 2006. - Vol. 48, $\mathrm{N} \quad 5 . \quad-\quad$ P. 342-362. - DOI: 10.1016/j.pcad.2005.11.003.

28. Frodl T., O'Keane $V$. How does the brain deal with cumulative stress? A review with focus on developmental stress, HPA axis function and hippocampal structure in humans // Neurobiology of disease. 2013. - Vol. 52. - P. 24-37. - DOI: 10.1016/J.NBD.2012.03.012.

29. Gold P.W. The organization of the stress system and its dysregulation in depressive illness // Molecular psychiatry. - 2015. - Vol. 20, N 1. - P. 32-47. - DOI: $10.1038 / \mathrm{mp} .2014 .163$.

30. Goshen I., Kreisel T., Ben-Menachem-Zidon O., Licht T., Weidenfeld J., Ben-Hur T., Yirmiya R. Brain interleukin-1 mediates chronic stress-induced depression in mice via adrenocortical activation and hippocampal neurogenesis suppression // Molecular psychiatry. - 2008. - Vol. 13, N 7. - P. 717-728. - DOI: $10.1038 /$ sj.mp.4002055.

31. Grace A.A. Dysregulation of the dopamine system in the pathophysiology of schizophrenia and depression // Nature Reviews Neuroscience. - 2016. Vol. 17, N 8. - P. 524-532. - DOI: 10.1038/nrn.2016.57.

32. Hegadoren K.M., O’Donnell T., Lanius R., Coupland N.J., Lacaze-Masmonteil N. The role of $\beta$ endorphin in the pathophysiology of major depression // Neuropeptides. - 2009. - Vol. 43, N 5. P. 341-353. - DOI: 10.1016/J.NPEP.2009.06.004.

33. Herman J.P., McKlveen J.M., Ghosal S., Kopp B., Wulsin A., Makinson R., Scheimann J., Myers B. Regulation of the hypothalamic-pituitary-adrenocortical stress response // Comprehensive Physiology. - 2016. - Vol. 6, N 2. - P. 603-621. - DOI: 10.3389/FNBEH.2013.00019. 
34. Hueston C.M., Deak T. The inflamed axis: the interaction between stress, hormones, and the expression of inflammatory-related genes within key structures comprising the hypothalamic-pituitary-adrenal axis // Physiology \& behavior. - 2014. - Vol. 124. - P. 7791. - DOI: 10.1016/J.PHYSBEH.2013.10.035.

35. Hunter C.A., Jones $S$. A. IL-6 as a keystone cytokine in health and disease //Nature immunology. - 2015. Vol. 16, N 5. - P. 448-457. - DOI: 10.1038/ni.3153.

36. Iyer S.S., Cheng G. Role of interleukin 10 transcriptional regulation in inflammation and autoimmune disease // Critical Reviews in Immunology. - 2012. Vol. 32, N 1. - P. 26-63. - DOI: 10.1615/CritRevImmunol.v32.i1.30.

37. Juruena M.F. Early-life stress and HPA axis trigger recurrent adulthood depression // Epilepsy \& Behavior. - 2014. - Vol. 38. - P. 148-159. - DOI: 10.1016/J.YEBEH.2013.10.020.

38. Kiecolt-Glaser J.K., Gouin J.P., Hantsoo L. Close relationships, inflammation, and health // Neuroscience \& Biobehavioral Reviews. - 2010. - Vol. 35, N $1 . \quad-\quad$ P. $33-38$. - $\quad$ DOI: 10.1016/J.NEUBIOREV.2009.09.003.

39. Koo J.W., Duman R.S. Evidence for IL-1 receptor blockade as a therapeutic strategy for the treatment of depression // Current opinion in investigational drugs. - 2009. - Vol. 10, N 7. - P. 664-671.

40. Koolhaas J.M., Bartolomucci A., Buwalda B.D., De Boer S.F., Flügge G., Korte S.M., Meerlo P., Murison R., Oliver B., Palanza P., Richter-Levin G., Sgoifo A., Steimer T., Stiedl O., van Dijk G., Wöhr M., Fuchs E. Stress revisited: a critical evaluation of the stress concept // Neuroscience \& Biobehavioral Reviews. - 2011. - Vol. 35, N 5. - P. 1291-1301. - DOI: 10.1016/j.neubiorev.2011.02.003.

41. Koolhaas J.M., De Boer S.F., Buwalda B., Van Reenen $K$. Individual variation in coping with stress: a multidimensional approach of ultimate and proximate mechanisms // Brain, behavior and evolution. 2007. - Vol. 70, N 4. - P. 218-226. - DOI: 218226.10.1159/000105485.

42. Le Merrer J., Becker J.A., Befort K., Kieffer B.L. Reward processing by the opioid system in the brain // Physiological reviews. - 2009. - Vol. 89, N 4. P. 1379-1412.

DOI: 10.1152/PHYSREV.00005.2009.

43. Leonard B., Maes M. Mechanistic explanations how cell-mediated immune activation, inflammation and oxidative and nitrosative stress pathways and their sequels and concomitants play a role in the pathophysiology of unipolar depression // Neuroscience \& Biobehavioral Reviews. - 2012. - Vol. 36, N 2. P. 764-785.

DOI: 10.1016/J.NEUBIOREV.2011.12.005.

44. Lucassen P.J., Pruessner J., Sousa N., Almeida O.F., Van Dam A.M., Rajkowska G., Swaab D.F., Czéh B. Neuropathology of stress // Acta neuropathologica. 2014. - Vol. 127, N 1. - P. 109-135. - DOI: 10.1007/s00401-013-1223-5.

45. McKlveen J.M., Myers B., Flak J.N., Bundzikova J., Solomon M.B., Seroogy K.B., Herman J.P. Role of prefrontal cortex glucocorticoid receptors in stress and emotion // Biological psychiatry. - 2013. - Vol. 74,
N $9 . \quad-\quad$ P. $\quad 672-679$. $\quad$ - $\quad$ DOI: 10.1016/J.BIOPSYCH.2013.03.024.

46. Merenlender-Wagner A., Dikshtein Y., Yadid G. The $\beta$-Endorphin Role in Stress-Related Psychiatric Disorders // Current drug targets. - 2009. - Vol. 10, N 11. P. 1096-1108. - DOI: 10.2174/138945009789735147.

47. Mesquita A.R., Correia-Neves M., Roque S., Castro A.G., Vieira P., Pedrosa, J., Palha J.A., Sousa N. IL-10 modulates depressive-like behavior // Journal of psychiatric research. - 2008. - Vol. 43, N 2. - P. 8997. - DOI: 10.1016/j.jpsychires.2008.02.004.

48. Molendijk M.L., de Kloet E.R. Immobility in the forced swim test is adaptive and does not reflect depression // Psychoneuroendocrinology. - 2015. - Vol. 62. P. 389-391. - DOI: 10.1016/j.psyneuen.2015.08.028.

49. O’Donovan A., Hughes B.M., Slavich G.M., Lynch L., Cronin M.T., O'Farrelly C., Malone K.M. Clinical anxiety, cortisol and interleukin-6: Evidence for specificity in emotion-biology relationships //Brain, behavior, and immunity. - 2010. - Vol. 24, N 7. - P. 10741077. - DOI: 10.1016/J.BBI.2010.03.003.

50. Ouyang W., Rutz S., Crellin N.K., Valdez P.A., Hymowitz S.G. Regulation and functions of the IL-10 family of cytokines in inflammation and disease // Annual review of immunology. - 2011. - Vol. 29. P. 71-109. - DOI: 10.1146/annurev-immunol-031210101312.

51. Rohleder N., Aringer M., Boentert M. Role of interleukin-6 in stress, sleep, and fatigue // Annals of the New York Academy of Sciences. - 2012. - Vol. 1261, N 1. - P. 88-96. - DOI: /10.1111/J.17496632.2012.06634.X.

52. Saraiva M., O'garra $A$. The regulation of IL-10 production by immune cells //Nature reviews immunology. - 2010. - Vol. 10, N 3. - P. 170. - DOI: $10.1038 /$ nri2711.

53. Slavich G.M., Irwin M.R. From stress to inflammation and major depressive disorder: a social signal transduction theory of depression // Psychological bulletin. - 2014. - Vol. 140, N 3. - P. 774-815. - DOI: $10.1037 / \mathrm{a} 0035302$.

54. Tank A.W., Lee Wong D. Peripheral and central effects of circulating catecholamines // Compr Physiol. 2015. - Vol. 5, N 1. - P. 1-15. - DOI: 10.1002/cphy.c140007.

55. Valentino R.J., Van Bockstaele E. Endogenous opioids: the downside of opposing stress // Neurobiology of stress. - 2015. - Vol. 1. - P. 23-32. - DOI: 10.1016/J.YNSTR.2014.09.006.

56. Van Reenen C.G., O'Connell N.E., Van der Werf J.T., Korte S.M., Hopster H., Jones R.B., Blokhuis H.J. Responses of calves to acute stress: individual consistency and relations between behavioral and physiological measures // Physiology \& Behavior. - 2005. Vol. 85, N 5. - P. 557-570. - DOI: 10.1016/J.PHYSBEH.2005.06.015.

57. Veenema A.H., Meijer O.C., de Kloet E.R., Koolhaas J.M., Bohus B.G. Differences in basal and stressinduced HPA regulation of wild house mice selected for high and low aggression //Hormones and Behavior. - 2003. - Vol. 43, N 1. - P. 197-204. - DOI: $10.1016 / \mathrm{S} 0018-506 \times(02) 00013-2$. 
58. Voorhees J.L., Tarr A.J., Wohleb E.S., Godbout J.P., Mo X., Sheridan J.F., Eubank T.D., Marsh C.B. Prolonged restraint stress increases IL-6, reduces IL-10, and causes persistent depressive-like behavior that is reversed by recombinant IL-10 // PloS one. - 2013. Vol. 8, N 3. - $\quad$ P. e58488. - DOI: 10.1371/JOURNAL.PONE.0058488.

59. Wong D.L., Tai T.C., Wong-Faull D.C., Claycomb R., Meloni E.G., Myers K.M., Carlezon W.A. Jr., Kvetnansky R. Epinephrine: A short-and long-term regulator of stress and development of illness // Cellular and molecular neurobiology. - 2012. - Vol. 32, N 5. - P. 737-748. - DOI: 10.1007/s10571-0119768-0.

60. Wu T.H., Lin C.H. IL-6 mediated alterations on immobile behavior of rats in the forced swim test via ERK1/2 activation in specific brain regions // Behavioural brain research. - 2008. - Vol. 193, N 2. P. 183-191. - DOI: 10.1016/J.BBR.2008.05.009. 